\title{
Research on the Role of Design Aesthetics in Modern Design
}

\author{
Yehua $\mathrm{Qu}^{1}$, Xuanbo $\mathrm{Mao}^{2} \mathrm{Dian}_{\mathrm{Li}^{3}}$ \\ ${ }^{1,3}$ Shenyang University of Chemical Technology, Department of Industry \& Art Design, Shenyang, China \\ ${ }^{2}$ Dalian University, School of Art, Dalian, China
}

\begin{abstract}
The essence of design is "to create things according to the laws of beauty". The factor of beauty is one of the most important criteria to evaluate the quality of design, and consumers will recognize those products with perfect combination of technology and form. With the expansion of the consumer society and the spread of the aesthetics of everyday life, the social status of design is increasingly prominent. Whether or not the design can be accepted or recognized by consumers in the end, aesthetics is one of the most important factors.
\end{abstract}

\section{Design aesthetics}

Design aesthetics, as the name suggests, should be about the aesthetics of design, or the discipline of exploring the beauty of design. Design aesthetics is a window to know design and understand it from the perspective of aesthetics.

"The research object of design aesthetics includes all fields of art design. From product to design process and design method; from the use and consumption of things to obtaining a variety of value, especially the acquisition of aesthetic value; from design plan, conception to design technology and manufacturing; from the practical function of things to the design of cultural taste, artistic form and style; from the form of creation to the thought and ideal of the creation; from the existence of design objects to the history of design art style and the research of art history, it involves many aspects". [2] [3]

"Design and Aes-thetics" may be more accurate than "Design Aesthetics" to accurately convey the "intersecting" characteristics of the combination of "design" and "aesthetics". Design aesthetics is the product of interdisciplinary integration. The study of it has been complicated since the theory of design itself remains to be perfected and the complexity of the aesthetics itself. ${ }^{[6]}$

In this cross field, we can not only study the design from the aesthetic point of view, but also develop the aesthetic research with the design as the object. Therefore, the design aesthetics can be an integral part of the theory of "design" and a branch of applied aesthetics.

\section{The design phenomena}

All the design phenomena in the field of traditional, modern and even the contemporary art include many aspects.

\subsection{The form system of the design}

This includes the connotation and extension of the design, the form features, the aesthetic law and the trend of development, etc.

\subsection{The designer}

This includes designer's knowledge structure, life experience, ideology, aesthetic pursuit and social ethics, etc.

\subsection{The impact and constrains}

This means the impact and constraints of scientific and technological level, material selection, market information and other factors on the design results during the design and production process.

\subsection{Local culture}

Local culture includes the cultural background, national tradition, popular trends and information feedback in the process of consumption of the designed product.

\subsection{The intersecting and connection}

The intersecting and connection between design and other related disciplines, such as culture, philosophy, art, sociology and psychology. In short, the common goal is to build a harmonious relationship between man and nature and society. 


\section{The characteristics of design aesthetics}

Design is a frontier subject that is based on technology and art and it combines the two in its application. Its research object, scope and application are different from the traditional art discipline. As a theoretical branch of design discipline, the theory of design aesthetics is also different from traditional aesthetic art research. Design aesthetics is an attempt to apply basic design principles to art design; it is applied not only in art design, but also in industrial design. As applied aesthetics, design aesthetics focuses on the specific aesthetic problems of basic necessities of life, which are closely related to day-to-day life. Its wide application not only beautifies the living environment, but also improves the quality of life. ${ }^{[6]}$

\subsection{Practicality}

Practicality is one of the most basic characteristics and it determines its wide application in life. Some ornaments in life can reflect more aesthetic feeling through the help of design aesthetics.

\subsection{Technology}

It is mainly manifested in the fact that design aesthetics has certain technical standards. Only when it reaches a certain level can it be recognized and then be accepted and show its value. Especially in enriching the value of aesthetic needs, it has gained better development opportunities.

\subsection{Aesthetic}

As a member of the aesthetic system, aesthetics is also the foundation for its continuous development. Because of aesthetics, design aesthetics has become more popular

\subsection{Innovation}

Design aesthetics is not stagnant, but developing in continuous innovation. Through the integration of innovative ideas and elements, it can show better aesthetic experience and proper value.

\subsection{Times}

Any aesthetics cannot escape the category of the times. The design aesthetics also changes with the development of the times. It adapts to the demand of the design aesthetics in the new era through the changes. If we throw away the times and then talk about design aesthetics, we will lose the most basic premise and become a rootless wood.

\section{Difficulties of design aesthetics}

Talking about difficulties of design aesthetics, there are four pairs of contradictions that should be dealt with first.

\subsection{People and products}

Traditional aesthetics attaches great importance to the subjective position of people in aesthetic activities. It emphasizes the design principle of "people oriented" in product design. Modern design cannot make this subjectivity absolute. The highest realm of design aesthetics is the harmony, perfect combination and unity between man and thing, man and environment, man and nature.

\subsection{Technology and art}

Design is directly constrained by the development level of modern science and technology. Factors related to technology development, such as materials, technology and information, would affect the artistic performance of design. Therefore, we must be good at utilizing the advantages and characteristics of modern technology and the aesthetic features of modern materials. Although the artistic expression of the design is metaphysical and super technical, it is necessary to pay attention to the change of the realistic aesthetic concept and take the initiative to accept the influence of the social fashion and aesthetic taste caused by the change of technology.

\subsection{Function and form}

Function refers to the basic functions, technologies, ideas and other material factors related to products. Unlike pure art, design first pays attention to practical utilitarianism, which is also a constituent element of design beauty. At the same time, we should also emphasize the aesthetic factors such as modelling, colour and decoration, which is the spiritual requirement of modern products and products related needs. The practical utilitarian and aesthetic forms are equally important, the material connotation of design will be greatly affected if function is ignored. Similarly, ignoring form equals to ignoring people's spiritual need for design.

\subsection{Subjective and objective}


Pure art creation is free; it belongs to subjective activity and it is the individual emotional expression behaviour of an artist. Although design also needs freedom of creation and subjective performance, they are limited. It must conform to objective requirements. Design must regard the acceptance of consumers and the public as the first priority. Design is a more objective activity that combines the designers with the public. ${ }^{[1][5]}$

\section{Research scopes of design aesthetics}

\subsection{The fundamental problems of design aesthetics}

\subsubsection{Design aesthetics}

Design aesthetics mainly includes the connotation, nature and composition of the beauty of design; the form and style of the beauty of design; the cultural connotation of the beauty of design; the form beauty of the design, the creation and realm of the beauty of design, etc.

\subsubsection{The history of the development of design aesthetics}

The history of the development of design aesthetics mainly includes the development history of design style, the history of design aesthetics, the design department (such as product design, process design, architectural design, etc.), and the history of aesthetics.

\subsubsection{Design department aesthetics}

Design department aesthetics mainly includes visual communication design aesthetics, product design aesthetics, architectural design aesthetics, environmental design aesthetics, process design aesthetics, etc.

\subsection{The aesthetic problems in the process of design activities}

\subsubsection{The aesthetic of the designer}

The aesthetic of the designer mainly includes the designer's aesthetic accomplishment, aesthetic ideal, artistic individuality, design thinking, etc.

\subsubsection{The law of aesthetic design}

The law of aesthetic design mainly includes the beauty of design and technology, the beauty of design and market, the beauty of design and production, the beauty of design and form rule, etc.

\subsubsection{Design aesthetic concepts}

Design aesthetic concepts includes the historical formation, evolution, modern form and future development trend of design aesthetics.

\subsubsection{Design aesthetic taste}

Design aesthetic taste mainly includes the social aesthetic interest, the individual aesthetic interest, the individuality and common characteristics of the beauty of design.

\subsection{Designing consumption aesthetics issue}

This mainly includes the connotation, ways, methods and implementation of aesthetic education.

\subsection{The educational problem of design aesthetic}

It mainly includes the connotation, ways, methods and implementation of aesthetic education. ${ }^{[1]}$

\section{Modern design aesthetics}

\subsection{Aesthetics and modern aesthetics}

Aesthetics is a branch of philosophy. Design aesthetics is a branch of aesthetics, it is a discipline about the idea of beauty. Design aesthetics is also a kind of applied aesthetics. It is a discipline that combines design practice and human life. It is the thinking of human about beauty of design in life and design practice. In fact, design aesthetics is quite different from general aesthetics. It has many unique characteristics and some of them have surpassed the category of traditional aesthetics. Design aesthetics has a unique feature.

Design aesthetics is a practical aesthetics and applied aesthetics, with its own aesthetic theories (functional design aesthetics, formal design aesthetics, psychological design aesthetics, evolutionism design aesthetics, and semiotics design aesthetics, etc.) Even though it shares the common aesthetic theory with art aesthetics, (for example, psychological aesthetics), the content and emphasis of design aesthetics are different. Design aesthetics must study the design practice combined with market economy, focusing more on the beauty of human sense, people's aesthetic experience in social life practice and the interaction between designer and people. 
The beauty of modern design is a new and unique beauty created by the development of modern society and the practice of modern design. Some characteristics of the beauty of modern design are determined by the combination of science and art, rationality and intuition, material and spirit, the comprehensiveness and uniqueness of philosophy and life. These characteristics include artificiality, practical nature, technology, innovativeness, functionality, life, sensory and mental integration, humanism and humanity beauty, etc. The aesthetic sense of the spirit and culture of the design is also an important part of the beauty of the design. The beauty of the design can be only the pleasure of the shape, the texture and the colour to the senses. It can also be a metaphor, the symbol of the identity of the cultural symbol and the confirmation of the self. ${ }^{[4]}$

\subsection{Features of the beauty of modern design}

The birth of modern design is to beautify people's lives by beautifying the industrial products produced in batches. It can be said that the core of modern design concept is to beautify life and pursue beauty. However, due to the technology and practicality of design, the aesthetics of design product is inseparable from innovation, convenience and practicality. Through these innovations and practicality, design is to transform and beautify people's lives, satisfy people's emotional needs and needs for comfortableness and convenience. That is to say the beauty of design is the beauty of practice, the beauty of life and the beauty of human nature.

\subsection{Problems to be solved in modern design aesthetics}

\subsubsection{The difference between design and art, the beauty of design and the beauty of art}

We should be clear about the difference between design and art and technology. Art is pure spiritual enjoyment or pure emotional experience. It is not utilitarian. Creation is personalized and cannot be duplicated. Design is closely combined with the needs and satisfaction of people's spiritual enjoyment, emotional experience and function. It is utilitarian, practical and it is mass production, standardized and replicable. Handicraft is between art and design. It can be used, but its production is personalized, manual, non-industrialized and standardized. Therefore, the beauty of design is different from the beauty of art.
One of the fundamental characteristics of traditional artistic beauty or natural beauty is non-utilitarian and non-practical. In design, the experience of beauty of all design products is based on the good functions of products, it must be closely integrated with practicality. This is the fundamental difference between designing products and works of art. ${ }^{[4]}$

\section{The relationship between design aesthetics and modern design}

The relationship between design aesthetics and modern design is dialectical. There has been a lot of discussion in the academic world. In a simple way, design aesthetics and the formation and development of design are synchronous and interacted. For one thing, technology led industrial civilization gave birth to modern design after the industrial revolution, which resulted in the emerging discipline of design aesthetics and the basic theoretical structure of it. For another thing, the research of design aesthetics in the field of aesthetics and theory also guides the development of modern design. It also analyses the problems arising from the development of modern design, and puts forward reasonable solutions and ways. As an inevitable product of the design of art theory and aesthetic development in modern society, the position of design aesthetics has not been questioned in the design and art world.

In today's era, technology is everywhere. Design is indispensable to life; technology and design are inseparable. Whether it is the beauty of the handicraft design or the rational beauty of modern industrial technology, it shows the indispensable position of design aesthetics in the design and industrial production.

\section{Conclusions}

Design comes from life. To conform the design aesthetics to the times is to give the design "positive energy" of this era. This is the responsibility that given by this era to the designers, it is also the proper meaning of design aesthetics. Design should be based on life. Life is changing and developing, design should also be developing and innovating, so that it can be compatible with the future development of our era. This is the meaning of existence of design aesthetics. The mission of modern design aesthetics is to explore the essence of modern design, create new forms and promote the development of modern design movement using the law of aesthetic. 


\section{References}

1. JX. Yao, Decoration. J. 141 (2005)

2. BQ. Huang, Journal of Hunan University of Science and Technology, Social Science Edition. J. 5 (2012)

3. LG. Zhang, Aesthetics of art design (Shandong Education Press, Ji'nan, 2002)

4. JY. Qiu, Beauty and Times. J. 12 (2010)

5. CP. Wang, GL. Zhang, Hundred Schools in Arts. J. 105 (2008)

6. XL. Wang, QX. Zhao, Design Theory. J. (2012) 